\title{
The Taste of Water
}

\section{H. J. ONGERTH, M.P.H., WILLIAM H. BRUVOLD, Ph.D., and A. L. KNUTSON, Ph.D.}

$\mathrm{T}$ HE TASTE of water in many arid parts of the world is affected by relatively high concentrations of the common dissolved minerals : calcium, magnesium, and sodium, in combination with chloride, sulfate, and carbonate. There are, however, no well-established limiting standards for these minerals. In the California State Department of Public Health, psychologists and engineers have joined to begin development of rational standards for these minerals in household water. This work takes on increasing importance because developing industry and increasing population in semi-arid and arid areas have led to greater consumption of high-mineral waters.

The Public Health Service and the World Health Organization have both issued standards for water quality which set conditional limits for some of the common minerals. The Public Health Service standards (1) are legally applicable to water used on common carriers for travelers in interstate traffic and are also used as guides or standards by all the States. The PHS standards set limits for chloride, sulfate, and total dissolved solids, stating that these three constituents should preferably not occur in excess of specified limits where other more suitable supplies are available. No limits for minerals are set for situations where more suitable waters are unavailable.

The WHO European Standards for Drinking Water (2) contain limits for magnesium, sulfate, and chloride. These limits are expressed as

Mr. Ongerth is assistant chief, bureau of sanitary engineering, California State Department of Public Health. Dr. Bruvold is a research fellow, School of Public Health, and Dr. Knutson is a lecturer in public health and director of the behavioral science project, University of California, Berkeley. the "approximate level above which trouble [taste or gastrointestinal irritation] may arise." The WHO International Standards for Drinking Water (3) apply to magnesium, calcium, sulfate, and chloride on the basis of "permissible" levels and "excessive" levels. None of these standards set "mandatory" limits for the minerals discussed here.

The WHO standards have no legal effect. They have been developed in an effort to offer technical guidance to the health administration of member States wishing to revise their regulations on water quality control. The general criteria on which the WHO standards are based are outlined in the preface to the European standards, which begins: "That water intended for human consumption must be free from chemical substances and organisms which might be a hazard to health is universally accepted. Supplies of drinking-water should, moreover, not only be safe - that is to say, free from danger to health-but should be as attractive to drink as circumstances permit. Coolness, absence of turbidity, absence of colour and of any disagreeable taste or smell are of the utmost importance in public supplies of drinkingwater."

Available records present only meager data as bases for limits on total dissolved solids, chloride, and sulfate in the PHS standards. No limits are set for the other major constituents. The WHO international and European standards set limits for calcium, magnesium, chloride, and sulfate without presenting bases for these limits. There is little evidence that meaningful and objective scientific procedures have been applied in establishment of any of these limits.

On the basis of present knowledge, only one of the six minerals, sulfate, is considered to have 
significant physiological effect on man at concentrations occurring in natural waters generally used for domestic purposes. For the other constituents, and perhaps for sulfate also, the taste of mineralized water, rather than physiological effects of minerals, may be the controlling factor in establishing standards. It should be noted, however, that investigators in England, Japan, and the United States have presented data indicating a possible correlation between the "hardness" of water and disease rates for cardiovascular illness such that lower disease rates occur where more mineralized waters are a vailable $(4,5)$. If this correlation can be definitely affirmed, there may be great value in establishing upper mineral levels for consumer acceptability of water.

Many communities now use waters containing minerals exceeding the limits found in the three sets of standards. Apparently some of these waters have consumer acceptability, or at least tolerance. Other waters are quite obviously unacceptable to the general public.

With relation to the PHS Drinking Water Standards, how highly mineralized might waters be where more suitable waters are not available? At some level below 2,500 parts per million of total dissolved solids, the water will be unacceptable to most consumers, and they will resort to use of alternative water sources. It appears that if a reliable method can be developed to determine consumer attitudes toward, and consumer acceptance of, waters of various mineral concentrations, it would be possible to establish "mandatory" limits in terms of these two factors for some or all of the major mineral constituents. One of the problems in attempting to develop information on consumer acceptability of water is created by the ability of people to adapt, within some limits, to waters of various composition. The limits of this adaptation, in degree and in time, are unknown.

Rationally and scientifically established standards would be most helpful for two particular reasons: first, to determine if a given water source is acceptable; second, to determine, when waters are to be demineralized, how much demineralization must be done. The second problem is becoming more important in areas where there is increasing necessity to use brack- ish ground waters for domestic water supply. In many areas of the southwest, the total available supply of fresh water is now used and, in some places, the demand for fresh water already exceeds the supply. In a few places, only brackish waters are available. Further, demineralization of brackish waters is, for some areas, already economically feasible. The cost depends on the amount of minerals in waters, as they occur in nature, and the amount which can be accepted in the treated waters. Therefore, the establishment of carefully defined standards will have a major impact on the economics of demineralization of brackish water.

Little information is available on the acceptability of mineralized waters. Research on human reactions to water used for domestic purposes is needed to parallel the technical studies on water demineralization now underway. Health officers and others responsible for approving domestic water supplies are, in some areas, already faced with the difficulty of making judgments regarding the acceptability of questionable waters used in developing communities. They lack the empirical evidence necessary for making such decisions. The California State Board of Public Health, sensitive to the need for objective data to deal with this growing problem, has requested that the California State Department of Public Health take the research steps necessary to obtain such information.

In response to this request, the bureau of sanitary engineeering of the State department of public health, in cooperation with the behavioral science unit of the School of Public Health at the University of California, has begun to develop methods whereby consumer acceptance of mineralized water can be measured. The Public Health Service has contributed to this new development by supporting a special research fellow at the School of Public Health to develop the experimental methods for carrying out such a project.

The work currently underway is intended to provide initial information regarding acceptance of waters having varying levels of mineralization and which are free from noticeable odor, color, and turbidity. Two methods of measurement are being designed to serve this purpose. One of the measuring devices 
will be used to assess individual attitudes regarding the water used in the community. The other device will be used to assess individual reactions to samples of water presented directly without any identification of the source or character of the sample. Information obtained from these two methods will give interlocking results that should be quite helpful in determining the upper levels of mineralization of water deemed acceptable by consumers.

One might ask: How can a person's reaction to the water available in his community be appraised? One method would be to ask a representative sample of persons from a particular community what they think of their water. This approach would use a questionnaire, preferably administered to one person at a time by trained interviewers. The data so obtained would provide the kind of information desired. However, a refinement of the questionnaire method appears to suit our present purpose better.

When the form of a questionnaire is changed from questions into simple declarative statements and the respondent is asked to state whether or not he agrees with the statement, this form becomes what is generally referred to as an attitude scale, a questionnaire that forms a scale. Such a scale has several qualities not found in a questionnaire, and thus it is the preferred method for collecting information, provided it can be used properly. One advantage of an attitude scale is that the responses of the interviewee can be given a numerical score, which represents his reaction to, or attitude toward, the object under study. If the respondent has a favorable attitude toward the water available to him, he should receive a high positive score on the scale. If he has a less favorable or negative attitude toward the water, he should receive a low positive or perhaps a negative score. By finding the typical or modal score of a representative sample from a community, we will be able to assign a "modal attitudinal rating" to each water supply studied.

Another advantage of the attitude scale is that reactions can be determined by using statements not obviously related to the topic under investigation. Thus, in areas where direct questions may fail to reveal the real feelings of the respondents, an indirect approach may suc- ceed. A third advantage of the scale orer the simple questionnaire is also important. The quality of the individual statements comprising the attitude scale can be assessed, in part, by statistical analyses of the responses given to each statement. Single statements can be analyzed to determine the relation between the responses given to the statement and groups of persons receiving either high or low total scores on the scale. Checks can be run to determine if the same persons receive the same or quite similar scores on repeated administrations of the same scale or when they are given an equivalent form of the original scale. Also, correlations can be determined between scale scores and direct behavioral measures, such as the amount of specially bottled water consumed per capita in a community, to assess the fundamental accuracy or validity of the scale.

As indicated, we are currently beginning to develop an appropriate attitude scale. After its accuracy has been shown to be sufficient for the task, by statistical analyses such as those discussed above, the scale will be used in field studies.

The other instrument being developed can be called a "taste scale," even though such a name or label is somewhat misleading. This taste scale, or procedure for obtaining individual assessments of unidentified samples of water, will be used in conjunction with the attitude scale to determine the acceptability of a particular water. At the current stage of development, the taste scale we envision will require a series of statements, perhaps 20 , that can be clearly and easily ranked according to their indication of water quality. The respondent will have these statements before him when asked to taste several unidentified samples of water under controlled conditions of presentation. Each sample will be rated or evaluated by assigning the one statement most appropriate to it. In this manner we plan to obtain the modal score or rating of many subjects for each of a fairly large group of water samples.

The taste scale must satisfy the same kinds of criteria used to evaluate the attitude scale. Before it is employed as a research instrument, the procedure must demonstrate sufficient reliability and validity to allow its use in a field study.

When the attitude scale and the taste scale 
have been standardized, we plan to use them in an extensive field study. By administering both scales to the same respondents in several different communities having waters of different levels of mineralization, we expect to obtain information that will reveal how each water is rated regarding its acceptability.

One of the most significant aspects of the research will be to obtain information relevant to several questions necessary for a complete understanding of reactions to mineralized waters. One question deals with habituation to mineralized water. Do people who live in a community for many years show toleration toward, or a like of, brackish water? If such habituation is found, will it be reflected on both the taste scale and the attitude scale? We hypothesize at this point that habituation to some waters will be revealed. We further hypothesize that if a tolerance to brackish water is indicated on both scales, the habituation will be due to a rather fundamental change in the perceived taste of the water. If acceptance of the community water is given only on the attitude scale and not on the taste scale under adequately designed control conditions, we hypothesize that such habituation will be an "I accept this poor tasting water though I would prefer something better" process, and not due to a more basic perceptual change.

Important also are the causal factors that might underlie a situation where the water is rated unacceptable on the attitude scale and acceptable, or perhaps as good, on the taste scale.
Possibly social pressures and other forces in a community rather than the esthetic reaction to the taste of the water itself may be the basis for either rejection or acceptance of a water.

The process of habituation indicates how the two scales can provide interlocking evidence pertinent to vital questions dealing with reactions to water. Although the data from this initial study in California will not answer all important questions related to establishing limits for common minerals in drinking water, they will provide a clearer understanding of the relation between amount and type of common minerals in community water and its general acceptance or rejection. The data should also bring to light questions for further research in an area that will become more important as the population increases and new water sources of low mineralization become scarcer.

\section{REFERENCES}

(1) U.S. Public Health Service : Drinking water standards. PHS Publication No. 956. U.S. Government Printing Office, Washington, D.C., 1962.

(2) World Health Organization : European standards for drinking water. Geneva, Switzerland, 1961.

(3) World Health Organization: International standards for drinking water. Geneva, Switzerland, 1958.

(4) Morris, J. N., Crawford, M. D., and Heady, J. A. : Hardness of local water supplies and mortality from cardiovascular disease in the county boroughs of England and Wales. J Brit Waterworks Assoc 43 : 602-607 (1961).

(5) Muss, D. L. : Relationship between water quality and deaths from cardiovascular disease. J Water works Assoc 54: 1371, November 1962.

\section{New Mental Retardation Branch}

Surgeon General Luther L. Terry of the Public Health Service has announced the establishment of the Mental Retardation Branch within the Division of Chronic Diseases as a further step toward providing services and facilities for the mentally retarded.

The newly organized branch, headed by Dr. Paul H. Pearson, will provide financial assistance to the States for planning comprehensive services for the mentally retarded.

Other activities include the support of applied research designed to yield new methods and techniques in prevention, diagnosis, and treatment; assistance in professional training; and the dissemination of information on mental retardation to professionals and the public. 